\title{
Screening HIV-positive men who have sex with men for hepatitis $C$ re-infection risk: is a single question on condom-use enough? A sensitivity analysis
}

Patrizia Künzler-Heule ${ }^{1,2}$, Sandra Engberg ${ }^{1,3}$, Manuel Battegay ${ }^{4,5}$, Axel J. Schmidt ${ }^{6,7}$, Katharina Fierz ${ }^{8}$, Huyen Nguyen ${ }^{9,10}$, Agnes Kocher ${ }^{1}$, Christiana Nöstlinger ${ }^{11,12}$, Benjamin Hampel ${ }^{9,10}$, Marcel Stöckle ${ }^{4,5}$, Charles Béguelin ${ }^{13}$, Julie Delaloye ${ }^{14}$, Patrick Schmid ${ }^{6}$, Markus Flepp ${ }^{15}$, Mathieu Rougement ${ }^{16}$, Dominique Laurent Braun ${ }^{9,10}$, Jan Fehr ${ }^{9,17}$, Dunja Nicca ${ }^{1,18^{*}}$ (1) and the Swiss HIV Cohort Study (SHCS)

\begin{abstract}
Background: Hepatitis C virus (HCV) is common in men who have sex with men (MSM) with HIV. The Swiss HCVree Trial targeted a micro-elimination by using a treat and counsel strategy. Self-reported condomless anal intercourse with non-steady partners was used as the selection criterion for participation in a counselling intervention designed to prevent HCV re-infection. The purpose of this study was to assess the ability of this criterion to identify men who engaged in other sexual risk behaviours associated with HCV re-infection.
\end{abstract}

Methods: Men who disclosed their sexual and drug- use behaviours during the prior 6 months, at study baseline, were included in the current study. Using a descriptive comparative study design, we explored self-reported sexual and drug-use risk behaviours, compared the odds of reporting each behaviour in men who reported and denied condomless anal intercourse with non-steady partners during the prior year and calculated the sensitivity/ specificity $(95 \% \mathrm{Cl})$ of the screening question in relation to the other at-risk behaviours.

Results: Seventy-two (61\%) of the 118 men meeting eligibity criteria reported condomless anal intercourse with non-steady partners during the prior year. Many also engaged in other potential HCV transmission risk behaviours, e.g., 52 (44\%) had used drugs. In participants disclosing drug use, 44 (37\%) reported sexualised drug use and $17(14 \%)$ injected drugs. Unadjusted odds ratios $(95 \% \mathrm{Cl})$ for two well-known risk behaviours were $2.02(0.80,5.62)$ for fisting and $5.66(1.49,37.12)$ for injecting drug use. The odds ratio for sexualised drug use - a potential mediator for increased sexual risk taking - was $5.90(2.44,16.05)$. Condomless anal intercourse with non-steady partners showed varying sensitivity in relation to the other risk behaviours examined (66.7-88.2\%).

Conclusions: Although condomless anal intercourse with non-steady partners was fairly sensitive in detecting other $\mathrm{HCV}$ relevant risk behaviours, using it as the only screening criterion could lead to missing a proportion of HIV-positive men at risk for $\mathrm{HCV}$ re-infection due to other behaviours. This work also points to the importance of providing access to behavioral interventions addressing other sexual and drug use practices as part of HCV treatment.

Trial registration: Clinical Trial Number: NCT02785666, 30.05.2016.

Keywords: HIV, Hepatitis C virus, Homosexuality, Male, Sexual behavior, Condoms

\footnotetext{
* Correspondence: dunja.nicca@unibas.ch

${ }^{1}$ Nursing Science, Department Public Health, Faculty of Medicine, University

of Basel, Bernoullistrasse 28, CH-4056 Basel, Switzerland

${ }^{18}$ Ressort MTT, University Hospital Basel, Basel, Switzerland

Full list of author information is available at the end of the article
}

(c) The Author(s). 2019 Open Access This article is distributed under the terms of the Creative Commons Attribution 4.0 International License (http://creativecommons.org/licenses/by/4.0/), which permits unrestricted use, distribution, and reproduction in any medium, provided you give appropriate credit to the original author(s) and the source, provide a link to the Creative Commons license, and indicate if changes were made. The Creative Commons Public Domain Dedication waiver (http://creativecommons.org/publicdomain/zero/1.0/) applies to the data made available in this article, unless otherwise stated. 


\section{Background}

In men who have sex with men (MSM) living with HIV, co-infection with hepatitis $\mathrm{C}$ virus $(\mathrm{HCV})$ has become a concern over the last 20 years [1]. An HCV RNAscreening of MSM with HIV $(n=3722)$ participating in the Swiss HIV Cohort Study (SHCS) between October 2015 and May 2016 showed a prevalence of 4.8\% $(n=$ 177) [2]. People living with an HIV/HCV co-infection show faster progression of liver fibrosis compared to people with $\mathrm{HCV}$ mono-infection and higher risk for liver-related morbidity and mortality [3]. Since the introduction of the new direct acting antivirals (DAAs) cure is possible in $95 \%$ of the cases, making microelimination of $\mathrm{HCV}$ a realistic target [4]. However, the population of MSM with HIV frequently present with $\mathrm{HCV}$ (re-) infections and current evidence shows that sexual transmission is one important source of (re-) infection [5]. Addressing sexual risk behaviour should become an essential component of HCV medical treatment [6].

In MSM, several sexual behaviours have been described as potentially risky, for example mucosally traumatic sexual behaviours including condomless anal intercourse (CAI), receptive fisting, rectal bleeding, anal douching, sharing of sex toys and group sex activities; nasally applied drugs; injection drug use and drug use in combination with sex [7-9]. Still, to-date, it remains controversial which risk behaviours are the most important ones regarding $\mathrm{HCV}$ transmission in MSM with HIV, and should subsequently constitute the most important targets for preventive efforts [10].

From 2015 to 2017, the Swiss HCVree Trial was conducted as an investigator-initiated substudy of the SHCS using a test, treat and counsel strategy with the goal to eliminate HCV in the MSM population with HIV [11]. An E-health assisted behavioural counselling intervention with nurses as counselors was developed and implemented with the aim to reduce sexual risk taking. MSM co-infected with HIV/HCV were asked to participate in the counseling intervention if they reported condomless anal intercourse with non-steady partners (nsCAI) the year prior to starting treatment [11]. Condomless anal intercourse was the only risk behaviour for which SHCS data was available [12] at the time of intervention development. However, its usefulness in selecting participants for the additional sexual risk reduction intervention remains questionable given that other sexual and drugusing behaviours are also important risk factors for HCV transmission. The current analysis was conducted to investigate the usefulness of nsCAI as the selection criterion for the behavioural intervention. This can provide important information for further studies. Specifically, the aims of this study were to (1) describe sexual and drug-using behaviours participants reported during Swiss
HCVree study baseline assessment and to compare those behaviours in MSM who did and did not report nsCAI during the prior year and to (2) examine the condom-use question's sensitivity and specificity in identifying men who engaged in other HCV relevant risk behaviours and who may, therefore, also benefit from risk reduction interventions.

\section{Methods}

A descriptive comparative study design was used to address the objectives and included a comprehensive assessment of social, medical and behavioural factors. Data were compared for differences between the two groups: those who reported nsCAI and those who denied nsCAI during the prior year.

\section{Setting and participants}

The Swiss HCVree Trial was implemented within the framework of the SHCS, an ongoing multicentre prospective observational study that started in 1988. Its participants have been shown to be highly representative of all known people living with HIV (PLWH) in Switzerland, [13] and modelling studies estimate that $84 \%$ of all MSM with HIV in Switzerland are followed in the SHCS [14]. During the Swiss HCVree Trial (20152017), all adult men with self-identified homosexual or bisexual preferences enrolled in the SHCS $(n=3722)$ were assessed for HCV ribonucleic acid (RNA) [2]. One hundered twenty-two (122) were diagnosed with HCV and treated with DAAs in one of eight specialized HIV clinics in Switzerland [11] and all but one individual were cured. Among the men treated with DAAs, a positive response to the nsCAI question in the SHCS during the prior year was used to select men who were invited to participate in the sexual risk reduction intervention performed by nurses.

\section{Data collection}

The data used in this analysis were retrieved from the SHCS database and the Swiss HCVree Trial baseline assessment. Data included sociodemographic characteristics (age, ethnicity/race, highest completed educational degree) and medical information about HIV from the SHCS database and HCV specific information from the Swiss HCVree Trial. At Swiss HCVree Trial baseline, participants were asked to complete a self-reported questionnaire about sexual and drug-use behaviours during the previous 6 months. Table 1 summarizes the data collected.

\section{Data analysis}

Analyses were conducted using the open source R statistical analysis software (Version 1.0.136 for Mac OS X). Participants' characteristics and self-reported at-risk 
Table 1 Data collected

\begin{tabular}{|c|c|c|c|}
\hline Database & Domain Variables assessed & Question & Answer \\
\hline \multirow{2}{*}{$\begin{array}{l}\text { SHCS, reported in } \\
\text { interview situation }\end{array}$} & \multicolumn{3}{|l|}{ Screening question } \\
\hline & $\begin{array}{l}\text { Selection criteria for sexual } \\
\text { risk reduction intervention }\end{array}$ & $\begin{array}{l}\text { "Over the last } 12 \text { months, did you have } \\
\text { unprotected anal intercourse with occasional } \\
\text { partners?" }\end{array}$ & Yes/no \\
\hline \multirow{16}{*}{$\begin{array}{l}\text { Swiss HCVree Trial, Self- } \\
\text { completed } \\
\text { questionnaires }\end{array}$} & \multicolumn{3}{|l|}{ Sociodemographic } \\
\hline & Partnership & $\begin{array}{l}\text { "Did you have a stable partnership in the last } 6 \\
\text { months?" }\end{array}$ & Yes/no \\
\hline & \multicolumn{3}{|l|}{ Risk Behaviours } \\
\hline & Sextoys & $\begin{array}{l}\text { "Over the last } 6 \text { months, did you use sextoys with } \\
\text { non-steady partners?" }\end{array}$ & Yes/no \\
\hline & Fisting & "Over the last 6 months, did you practice fisting?" & Yes/no \\
\hline & \multirow[t]{7}{*}{ Drug use } & $\begin{array}{l}\text { "Did you use one or more of the following } \\
\text { substances in the last } 6 \text { months?" }\end{array}$ & \\
\hline & & Cocaine & Yes/no \\
\hline & & Y-butyrolactone/Y-hydroxybutyric acid (GHB/GBL) & Yes/no \\
\hline & & crystal methamphetamine (CM) & Yes/no \\
\hline & & ketamine & Yes/no \\
\hline & & mephedrone & Yes/no \\
\hline & & $\begin{array}{l}\text { "If your answer is yes, how did you take the } \\
\text { substance(s)?" }\end{array}$ & $\begin{array}{l}\text { injection (slammed)/ intranasal/orally/ } \\
\text { smoked/ mucosally (anal) }\end{array}$ \\
\hline & Sexualised drug use & $\begin{array}{l}\text { "If your answer is yes, did you take any of the } \\
\text { above-mentioned substance(s) in combination } \\
\text { with sex?" }\end{array}$ & Yes/no \\
\hline & \multicolumn{3}{|l|}{ Psychological constructs } \\
\hline & $\begin{array}{l}\text { Attitudes towards } \\
\text { condom use }\end{array}$ & $\begin{array}{l}\text { Sexual risks scale-attitudes toward condom use } \\
\text { [15] } 13 \text { items rated on a 5-point Likert scale }\end{array}$ & $\begin{array}{l}1 \text { (I don't agree at all) to } 5 \text { (I completely } \\
\text { agree). Possible scores range from } 13 \text { to } \\
65\end{array}$ \\
\hline & Condom self-efficacy & $\begin{array}{l}\text { Self-efficacy for negotiating condom use [16], } 5 \\
\text { items rated on a } 1-10 \text { scale }\end{array}$ & $\begin{array}{l}0 \text { (I cannot) to } 10 \text { (I am sure that I can). } \\
\text { Possible scores range from } 0 \text { to } 50\end{array}$ \\
\hline
\end{tabular}

sexual and drug-use behaviours were analysed descriptively. Depending on the level of measurement and distribution of variables, frequencies, percentages, means and standard deviations (SD), or median and interquartile range (IQR) were calculated. Based on the SHCS data, participants were divided into two groups: those who reported no sex with non-steady partners or only protected anal intercourse during all sexual encounters during the last 12 months (i.e. without nsCAI) and those reporting nsCAI. Baseline characteristics, attitudes and self-efficacy regarding condom use were compared in the two nsCAI groups. Chi-square tests were used to compare categorical variables and the student's t-test (for age, which was normally distributed) or MannWhitney U tests (for years since HIV diagnosis and scores on the attitudes toward condom use and selfefficacy questionnaires, which were not normally distributed) were utilised to compare continuous variables. Odds ratios and their 95\% confidence intervals (CI) were calculated to examine the association between nsCAI and the other risk behaviours assessed. Multivariable logistic regression was conducted to determine if adjusting for age and duration of $\mathrm{HCV}$ affected the relationship between nsCAI and the other risk behaviors. We used a manual stepwise backward elimination. MedCalc online software (https://www.medcalc.org/calc/diagnostic test.php) was used to calculate the sensitivity and specificity (including 95\% CI) of the condom use screening question with non-steady sexual partners in relation to the other at-risk sexual and drug use behaviours.

\section{Results}

During the Swiss HCVree Trial baseline assessment, 118 of 122 participants disclosed their sexual and drug-use behaviours and were included in the current study, see Fig. 1.

Based on SHCS data, 72 (61\%) MSM reported nsCAI and $46(39 \%)$ reported no nsCAI during the 12 months prior to enrollment in the Swiss HCVree Trial. There were no significant differences in the two groups' sociodemographic characteristics. There were significant group differences in the years since $\mathrm{HCV}$ diagnosis; MSM with 


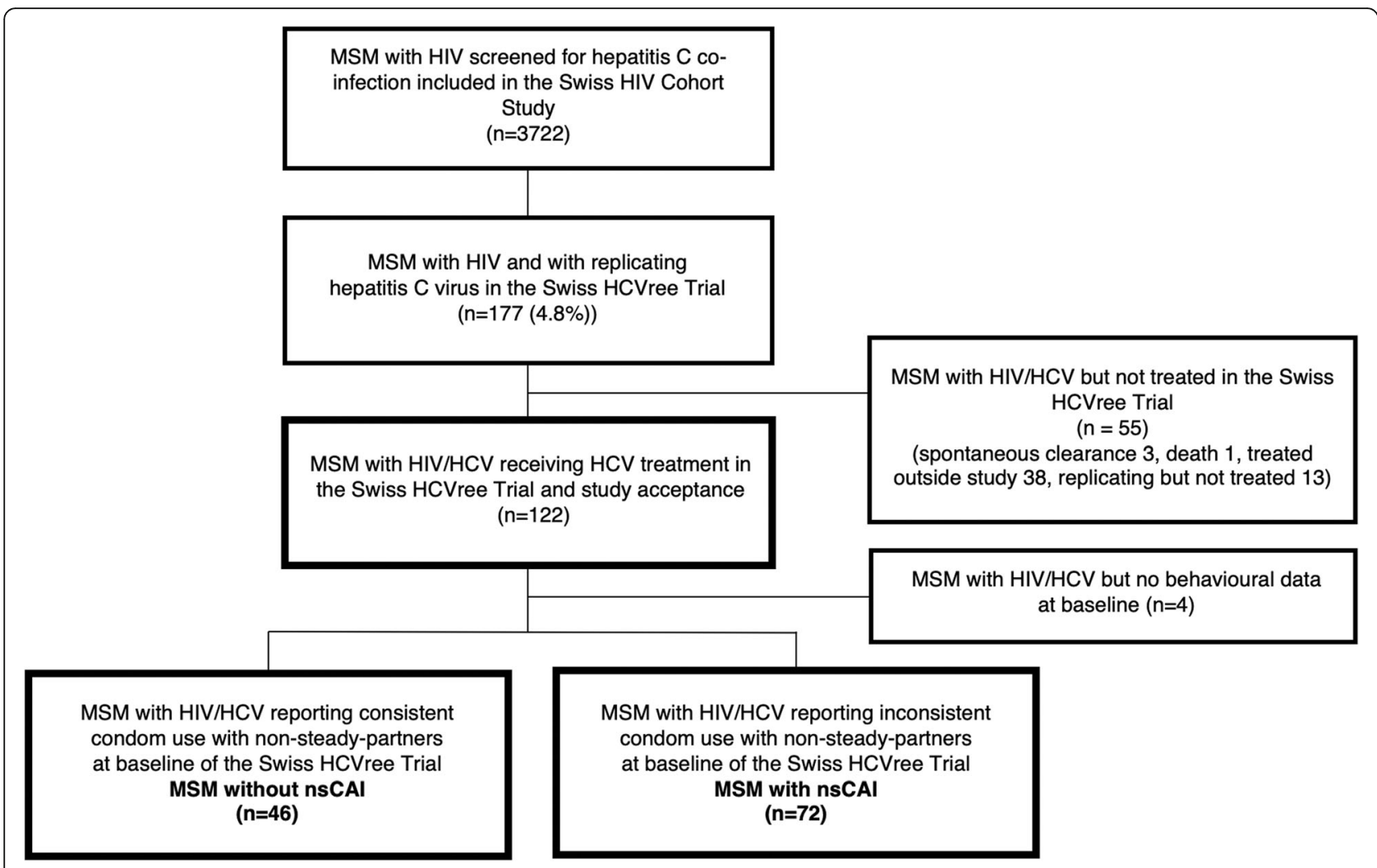

Fig. 1 Flowchart Swiss HCVree Trial and group building according to men's response to the nsCAl screening question

nsCAI had a shorter median duration of 1.9 years $(0.9-$ 5.1) compared to MSM without nsCAI with a median duration of 4.8 years (2.1-10.3). Participants without nsCAI scored significantly more positive attitudes toward condom use and had higher self-efficacy related to condom use than men with nsCAI (median score $=44.00$ vs. $39.00, p=.023$ and median score $=40.72$ vs. $29.23, p<.001$ respectively).

Many men reported engaging in a variety of sexual or drug-use behaviours identified as risk factors for HCV-infection: 25 (24\%) shared sextoys, 28 (25\%) practised fisting and 52 (44\%) used drugs during the prior 6 months. In participants who answered the drug-use questions, 44 (37\%) reported sexualised drug use and 17 (15\%) injected drugs. Participants reported using the following drugs: 30 (26\%) used $\gamma$ butyrolactone/ $\gamma$-hydroxybutyric acid (GHB/GBL), 26 (22\%) cocaine, $22(19 \%)$ crystal methamphetamine, 11 (9\%) ketamine and 10 (9\%) mephedrone (Table 2). Those with nsCAI during the 12 months prior to treatment were more likely to have engaged in other risky sexual behaviours than those without nsCAI although the odds in the two groups were only statistically significant for drug use, drug use during sex and injecting drugs. Adjusting for age and/or HCV duration did not change the relationship between nsCAI and the other risk behaviours examined in terms of the direction or significance of the odds ratios.

Odds ratios for two sexual behaviours with established transmission risk were $2.02(0.80,5.62)$ for fisting and $5.66(1.49,37.12)$ for injecting drug use. Sexualised drug use, a potential mediator for increasing other risk behaviours, showed an odds ratio of $5.90(2.44,16.05)$, see Table 2.

Table 3 summarizes the results of analyses examining the sensitivity and specificity of reporting consistent condom-use with non-steady partners at study baseline in identifying men who did not engage in the other atrisk behaviours examined. The nsCAI question had the highest sensitivity in relation to the question about injecting drugs (88.2\%) and lowest for sharing sex toys (66.67\%). Specificity was low in all analysed risk behaviours $(41.18-57.58 \%)$.

\section{Discussion}

The MSM co-infected with HIV/HCV in this study practiced various sexual and drug use behaviours associated with $\mathrm{HCV}$ transmission risk in addition to condomless sex. While nsCAI was associated with higher odds of engaging in other behaviours, based on our findings, relying only on this question to identify men at risk for $\mathrm{HCV}$ re-infection is likely miss a proportion of MSM 
Table 2 Sociodemographic and HCV-related risk behaviours in the last 6 months at study baseline

\begin{tabular}{|c|c|c|c|c|c|c|}
\hline $\begin{array}{l}\text { Sociodemographic and } \\
\text { HCV-related risk behaviours } \\
\text { at study baseline }\end{array}$ & $\begin{array}{l}\text { Total } \\
(n=118)\end{array}$ & $\begin{array}{l}\text { Participants } \\
\text { without nsCAl } \\
(n=46)\end{array}$ & $\begin{array}{l}\text { Participants with nsCAl } \\
(n=72)\end{array}$ & $\begin{array}{l}\text { Univariable Odds Ratio } \\
(95 \% \mathrm{Cl})\end{array}$ & $\begin{array}{l}\text { Multivariable Adjusted } \\
\text { OR }(95 \% \mathrm{Cl}) \text { for age } \\
\text { and HCV duration }\end{array}$ & $\begin{array}{l}\text { Adjusted OR } \\
\text { ( } 95 \% \text { Cl) for } \\
\text { HCV duration }\end{array}$ \\
\hline Age, mean (sd) & $\begin{array}{l}46.6(+/- \\
9.2)\end{array}$ & $49.0(+/-9.1)$ & $45.1(+/-9.1)$ & $0.64(0.41,0.96)^{a}$ & & \\
\hline $\begin{array}{l}\text { HCV duration, median } \\
\text { (IQR) }\end{array}$ & $\begin{array}{l}2.9(1.1- \\
7.1)\end{array}$ & $4.8(2.1-10.3)$ & $1.9(0.9-5.1)$ & $0.87(0.80,0.94)$ & & \\
\hline $\begin{array}{l}\text { Sharing sextoys, } n(\%) \\
(n=104 / 38 / 66)^{b}\end{array}$ & $25(24)$ & $7(18)$ & $18(28)$ & $1.53(0.58,4.40)$ & $1.05(0.36,3.21)$ & $\begin{array}{l}1.08(0.37 \\
3.29)\end{array}$ \\
\hline $\begin{array}{l}\text { Fisting, } \mathrm{n}(\%)(n=114 / \\
43 / 71)^{\mathrm{b}}\end{array}$ & $28(25)$ & $7(16)$ & $21(30)$ & $2.02(0.80,5.62)$ & $2.12(0.78,6.31)$ & $\begin{array}{l}1.92(0.72, \\
5.60)\end{array}$ \\
\hline $\begin{array}{l}\text { Drug use, } \mathrm{n}(\%)(n=117 / \\
45 / 72)^{\mathrm{b}}\end{array}$ & $52(44)$ & $8(18)$ & $44(61)$ & $7.27(3.08,18.91)$ & $5.58(2.26,15.02)$ & $\begin{array}{l}5.79(2.37 \\
15.42)\end{array}$ \\
\hline GHB/GBL, n (\%) & $30(26)$ & $3(7)$ & $27(38)$ & $8.60(2.78,37.87)$ & $6.64(2.04,30.18)$ & $\begin{array}{l}6.91(2.15 \\
31.07)\end{array}$ \\
\hline Cocaine, n (\%) & $26(22)$ & $6(13)$ & $20(28)$ & $2.56(0.99,7.55)$ & $2.36(0.85,7.39)$ & $2.49(0.91,7.6)$ \\
\hline $\begin{array}{l}\text { Crystal methamphetamine, } \\
\text { n \%) }\end{array}$ & $22(19)$ & $1(2)$ & $21(29)$ & $18.48(3.63,338.0)$ & $15.47(2.89,288.31)$ & $\begin{array}{l}15.91(3.01 \\
294.78)\end{array}$ \\
\hline Ketamine, n (\%) & $11(9)$ & $2(4)$ & $9(14)$ & $3.12(0.76,21.14)$ & $3.55(7.82,25.71)$ & $\begin{array}{l}3.55(7.82 \\
25.71)\end{array}$ \\
\hline Mephedrone, n (\%) & $10(9)$ & - & $10(15)$ & & & \\
\hline $\begin{array}{l}\text { Use of any of the drugs } \\
\text { listed above during sex, } \mathrm{n} \\
(\%)(n=116 / 45 / 71)^{\mathrm{b}}\end{array}$ & $44(38)$ & $7(16)$ & $37(52)$ & $5.90(2.44,16.05)$ & $4.42(1.73,12.52)$ & $\begin{array}{l}4.63(1.84 \\
12.92)\end{array}$ \\
\hline $\begin{array}{l}\text { Reporting injection of } \\
\text { drugs, } \mathrm{n}(\%)(n=117 / 45 / 72)^{\mathrm{b}}\end{array}$ & $17(15)$ & $2(4)$ & $15(21)$ & $5.66(1.49,37.12)$ & $4.45(1.10,30.15)$ & $\begin{array}{l}4.53(1.13 \\
30.51)\end{array}$ \\
\hline
\end{tabular}

anit 10 years

${ }^{b}$ specified how many HIV-positive MSM answered the question ( $n=$ total group/without nsCAI/with nsCAI)

with HIV at risk for HCV due to other behaviours. Between 16 to $18 \%$ of the men who denied nsCAI reported engaging in other behaviors that have been associated with an increased risk of $\mathrm{HCV}$ re-infection. Eighteen percent (18\%) of those who denied nsCAI reported using drugs. This is an important finding as drug use is seen as a potential mediator for increased sexual risk-taking $[17,18]$.

Condom use was the only risk behaviour available for all men in the SHCS and was for this reason used as the criterion for selecting men to participate in the sexual risk reduction behavioural intervention portion of the

Table 3 Sensitivity analysis of screening question "nsCAl" to identify other probable risk behaviours for HCV re-infection

\begin{tabular}{lll}
\hline Risk Behaviours & Sensitivity $^{\mathrm{a}}(\%)(95 \% \mathrm{Cl})$ & Specificity $^{\mathrm{b}}(\%)(95 \% \mathrm{Cl})$ \\
\hline Any drug use & $84.62(71.92-93.12)$ & $57.58(44.79-69.66)$ \\
Sexualised drug use & $84.09(69.93-93.36)$ & $52.70(40.75-64.43)$ \\
Injecting drug use & $88.24(63.56-98.54)$ & $43.56(33.72-53.80)$ \\
Fisting & $75.00(55.13-89.31)$ & $43.18(32.66-54.18)$ \\
Sharing of sex toys & $66.67(48.17-82.04)$ & $41.18(30.61-52.38)$
\end{tabular}

${ }^{a}$ The probability that HIV-positive MSM report a selected risk behaviour will also report nsCAl

${ }^{\mathrm{b}}$ The probability that HIV-positive MSM will deny nsCAI if they are not engaging in other selected other risk behaviours
Swiss HCVree Trial [19]. Despite our use of this inclusion criterion, its discriminatory value in identifying men at high risk for HCV re-infection was unclear. However, a recent study from London found that CAI was a significant risk factor for acute $\mathrm{HCV}$ infection in MSM and in one third of participants it was the only risk factor [9]. In contrast to our study, MSM received care in a sexual health clinic and benefitted from a multidisciplinary prevention approach including harm reduction services whereas in our study, HCV treatment was given in specialised medical HIV clinics. In line with other investigations in MSM with HIV, study participants reported various behaviours other than nsCAI that potentially increased their risk of HCV sexual transmission [9]. It has been well documented that condoms are less attractive in the MSM community - largely due to the common understanding and awareness that HIV treatment is preventive in terms of HIV transmission [20]. Decreasing trends of condom use was confirmed in a systematic review of studies across high-income countries [21]. Champenois et al. [22] reported that for MSM with HIV the main reasons for not using condoms were serosorting and being on antiretroviral therapy (ART) with undetectable viral loads. While these traditional HIV-related risk reduction strategies (serosorting and 
effective HIV treatment) have been shown to prevent the transmission of HIV, they have little or no effect in preventing $\mathrm{HCV}$ or other sexually transmitted diseases.

In our study, MSM with HIV and nsCAI were more likely to engage in other risk behaviours compared to those without nsCAI but the relationship was only statistically significant for drug-use and sexualized drug-use. However, due to the small sample size, our study was probably only adequately powered to detect large differences in the groups. They were two-times more likely to practice fisting and six times more likely to report sexualised drug use. The sensitivity of the nsCAI question was $85 \%$ in relation to drug use. Nevertheless, our findings indicate that using nsCAI as the only risk behaviour criterion to select men for the behavioural intervention was likely to have resulted in failure to include between 12 and 34\% of those engaging in other risk behaviours. Each single behaviour included in the current analysis carries a specific HCV transmission risk; however, which behaviour or combinations of behaviours carry the highest risks is currently less clear and cannot be answered with this study design.

Our results are in line with other studies showing associations between higher rates of drug use/sexualised drug use and risk behaviors [18, 23, 24]. A substantial proportion of our participants reported drug use (44\%). Among the men who answered these questions (116 for sexualized drug use and 117 for injecting drugs), 38\% reported sexualised drug use and $15 \%$ reported injecting substances. In comparison, in two earlier studies on MSM with HIV- one from Madrid $(n=742)$ [23] and one from England/Wales $(n=392)[24]-29.1-29.5 \%$ of participants indicated sexualised drug use and 10.1-16\% injecting drug use. Our group's higher rate of sexualised drug use might reflect differences in the study population, especially the fact that our sample's MSM with HIV were all co-infected with HCV. Several studies have found elevated rates of sexualised drug use in MSM coinfected with $\mathrm{HIV} / \mathrm{HCV}$, affirming associations between sexual HCV transmission and higher risk taking behaviours when using substances $[25,26]$. Another possible explanation for our group's high rates of sexualised drug use may be related to the study setting: most of our participants were recruited at the centres in Zurich, a town known for a comparably high prevalence of sexualised drug use. In the European MSM Internet Survey (EMIS2010), which compared 44 European cities in relation to illicit drug use in MSM, place of residence was the strongest predictor. Zurich reported a 7\% prevalence of using one of the four drugs typically used during sex, ranking sixth of the 44 cities studied, just after UK and Spanish cities [8]. In another European survey conducted among MSM in 13 cities, overall prevalence of sex associated with drug use was $11.8 \%$ (when measured at the last sexual encounter), and was more frequently reported by MSM with HIV [27].

The four substances typically used during sex were all reported in our study, with GBL/GHB being the most common (25\%), followed by crystal methamphetamine (19\%). In EMIS (European MSM Internet Survey), percentages of GBL/GHB use were quite similar, but crystal methamphetamine use was lower [8] than in our study, suggesting a surge in its popularity in MSM with HIV. The frequency of cocaine use was also high (22\%) comparable to rates reported in the UK ASTRA trial in MSM with HIV or for Zurich in EMIS $[8,18]$. To date, few studies investigating sexualized drug use have included cocaine. However, our results indicate that cocaine may be more common (19\%) in sexual contexts than expected.

This study has several limitations. The study's crosssectional design precluded any causal inferences about the associations between nsCAI and other behaviours risky for $\mathrm{HCV}$ re-infection. During analysis, we identified some limitations in the formulation of questions, e.g., we did not ask about the distinction between insertive or receptive fisting. While self-report questionnaire data may be biased, especially for such sensitive domains as sexual and drug use behaviour, it is often perceived as superior compared to being asked by someone else because of reduced social desirability bias [28]. Given the limited number of MSM co-infected with $\mathrm{HIV} / \mathrm{HCV}$ in Switzerland, the study sample (118 participants) was small. The small sample size may have limited our ability to detect statistically significant differences in behaviors in the nsCAI and non-nsCAI groups that were clinically meaningful. One strength of the study is that Swiss HCVree Trial (the source of data for this study) screened and treated all participants co-infected with $\mathrm{HCV}$ in the SHCS, so the sample is likely to be representative of MSM with HIV living in Switzerland [13].

\section{Conclusions}

Our findings support existing research that MSM coinfected with $\mathrm{HIV} / \mathrm{HCV}$ engage in various sexual and drug-use behaviours, potentially increasing their risk of HCV re-infection. Men who reported using condoms inconsistently with non-steady partners were more likely to report engaging in the other sexual and drug-use behaviors measured although the differences were only statistically significant for the drug-use behaviors. nsCAI was fairly sensitive in identifying men who also engaged in other risk behaviours, but relying only on it to identify men at risk for $\mathrm{HCV}$ infection would miss a proportion of MSM with HIV practicing other potentially modifiable behaviours. Based on our findings we recommend comprehensive screening of potential risk behaviours to identify men whose sexual and drug use behaviors 
increase their risk for $\mathrm{HCV}$ infection. We recommend offering all MSM co-infected with $\mathrm{HIV} / \mathrm{HCV}$ behavioural interventions designed to reduce sexual and drug use risk behaviours.

\section{Abbreviations}

Cl: Confidence interval; DAAs: Direct acting antivirals; GBL/GHB: ybutyrolactone/Y-hydroxybutyric acid; HCV: Hepatitis C virus; IQR: Interquartile range; MSM: Men who have sex with men; nsCAl: Condomless anal intercourse with non-steady partners; SD: Standard deviation; SHCS: Swiss HIV Cohort study; STI: Sexual transmitted infections

\section{Acknowledgements}

We thank all men who have participated in the Swiss HCVree Trial and all investigators and study nurses from the centres for their work and Chris Shultis for editing the manuscript.

Members of the Swiss HIV Cohort Study:

Anagnostopoulos A, Battegay M, Bernasconi E, Böni J, Braun DL, Bucher HC, Calmy A, Cavassini M, Ciuffi A, Dollenmaier G, Egger M, Elzi L, Fehr J, Fellay J, Furrer H, Fux CA, Günthard HF (President of the SHCS), Haerry D (deputy of "Positive Council"), Hasse B, Hirsch HH, Hoffmann M, Hösli I, Huber M, Kahlert CR (Chairman of the Mother \& Child Substudy), Kaiser L, Keiser O, Klimkait T, Kouyos RD, Kovari H, Ledergerber B, Martinetti G, Martinez de Tejada B, Marzolini C, Metzner KJ, Müller N, Nicca D, Paioni P, Pantaleo G, Perreau M, Rauch A (Chairman of the Scientific Board), Rudin C, Scherrer AU (Head of Data Centre), Schmit P, Speck R, Stöckle M (Chairman of the Clinical and Laboratory Committee), Tarr P, Trkola A, Vernazza P, Wandeler G, Weber R, Yerly S.

\section{Authors' contributions}

$\mathrm{PKH}, \mathrm{SE}, \mathrm{KF}$ and DN designed the manuscript concept; MB, AJS, BH, MSt, CB, $J D, P S, M F, M R, D L B, J F$ and $D N$ were responsible for the design and implementation of the Swiss HCVree Trial in the participating centres including data collection; $\mathrm{PKH}$, SE, and $\mathrm{NH}$ performed statistical analysis; AK, $\mathrm{CN}$ provided methodological support and regularly contributed to the interpretation of data during the process of data analysis; $\mathrm{PKH}$, SE and DN wrote the first draft of the manuscript; MG, AJS, KF, HN, AK, CN, BH, MSt, CB, $J D, P S, M F, M R, D L B$, JF read and critically reviewed the manuscript draft. All authors read and approved the final manuscript.

\section{Funding}

This study has been financed within the framework of the Swiss HIV Cohort Study, supported by the Swiss National Science Foundation (grant \#177499), by SHCS project 772 and by the SHCS research foundation. The SHCS data used for this study were collected by seven SHCS centres including overall five Swiss University Hospitals, two Cantonal Hospitals, 15 affiliated hospitals and 36 private physicians (listed in http://www.shcs.ch/180-health-careproviders). Representatives of SHCS centres were involved in the process of data collection, data analysis and publication.

The medication for the Swiss HCVree Trial was funded by Merck. No funding was received for this study and the development and evaluation of the behavioural intervention.

\section{Availability of data and materials}

The individual level datasets generated and/or analysed during the current study are not publicly available because open access to all SHCS data is currently not possible. This data is too dense and comprehensive to preserve patient privacy in patients with HIV infection. Free access to the data would currently not be compatible with the SHCS informed consent and with preserving patient privacy. Investigators with a request for selected data should send a proposal to the corresponding author. The provision of data will be considered by the study team and the Scientific Board of the SHCS.

\section{Ethics approval and consent to participate}

The Swiss HCVree Trial was approved by the lead ethic committee in Zurich, Switzerland (https://kek.zh.ch/internet/gesundheitsdirektion/kek/de/home. html) under the reference number BASEC 2016-00131 (locally responsible for the University Hospital Zurich and Klinik im Park). Local ethics committee Bern (University Hospital Bern), Northwest/Central (EKNZ) (University Hospital Basel), Geneva (University Hospital of Geneva), Ostschweiz (EKOS) (Cantonal
Hospital St. Gallen), Ticino (Regional Hospital Lugano), and Vaud (University Hospital Center Lausanne) approved as well. All participants provided written informed consent prior to participation.

\section{Consent for publication}

Not Applicable.

\section{Competing interests}

PKH received consultancy fees from Sigma-Tau, Norgine, AbbVie and grants from ViiV, Merck, and Janssen; all outside the submitted work.

SE has no conflict of interest.

MB has no conflict of interest.

KF has no conflict of interest.

$\mathrm{NH}$ has no conflict of interest.

AJS has no conflict of interest.

AK reports grant from Merck outside submitted work.

$\mathrm{CN}$ has no conflict of interest.

$\mathrm{BH}$ has no conflict of interest.

MSt reports board memberships with AbbVie, Gilead, and MSD.

CB reports fees from AbbVie, MSD, and Gilead, outside the submitted work.

JD has no conflict of interest.

PS received travel grants from Merck, outside submitted work.

MF has no conflict of interest.

MR reports grants from MSD and ViiV outside submitted work.

DLB received consultancy fees from Merck, Gilead, and ViiV.

JF is a member of the Federal Commission for Sexual Health. He received research, educational and travel grants from Janssen, Merck and ViiV Healthcare.

DN reports grants from Merck, Janssen, and ViiV outside submitted work.

\section{Author details}

${ }^{1}$ Nursing Science, Department Public Health, Faculty of Medicine, University of Basel, Bernoullistrasse 28, CH-4056 Basel, Switzerland. ${ }^{2}$ Department of Gastroenterology/Hepatology and Department of Nursing Development, Cantonal Hospital St. Gallen, St. Gallen, Switzerland. ${ }^{3}$ University of Pittsburgh, School of Nursing, Pittsburgh, PA, USA. ${ }^{4}$ Division of Infectious Diseases and Hospital Epidemiology, University Hospital Basel, Basel, Switzerland. ${ }^{5}$ Medical Faculty, University of Basel, Basel, Switzerland. 'Division of Infectious Diseases, Cantonal Hospital St. Gallen, St. Gallen, Switzerland. ${ }^{7}$ Sigma Research, London School of Hygiene and Tropical Medicine, London, UK. ${ }^{8}$ Zurich University of Applied Sciences (ZUAS), Winterthur, Switzerland. ${ }^{9}$ Division of Infectious Diseases and Hospital Epidemiology, University Hospital Zurich, Zurich, Switzerland. ${ }^{10}$ Institute of Medical Virology, University of Zurich, Zurich, Switzerland. " Department of Public Health, Institute of Tropical Medicine, Antwerp, Belgium. ${ }^{12}$ Department of Applied Psychology, University of Wien, Vienna, Austria. ${ }^{13}$ Department of Infectious Diseases, Bern University Hospital and University of Bern, Bern, Switzerland. ${ }^{14}$ Department of Intensive Care Medicine, University of Lausanne and University Hospital, Lausanne, Switzerland. ${ }^{15}$ Center for Infectious Diseases, Klinik im Park, Zurich, Switzerland. ${ }^{16}$ Primary Care Medicine Unit, University Hospital of Geneva, Geneva, Switzerland. ${ }^{17}$ Department of Public Health, Epidemiology, Biostatistics and Prevention Institute, University of Zurich, Zurich, Switzerland. ${ }^{18}$ Ressort MTT, University Hospital Basel, Basel, Switzerland.

Received: 17 April 2019 Accepted: 10 September 2019

Published online: 18 September 2019

\section{References}

1. Platt L, Easterbrook P, Gower E, McDonald B, Sabin K, McGowan C, Yanny I, Razavi $\mathrm{H}$, Vickerman P. Prevalence and burden of HCV co-infection in people living with HIV: a global systematic review and meta-analysis. Lancet Infect Dis. 2016;16(7):797-808.

2. Braun DL, Hampel B, Martin E, Kouyos R, Kusejko K, Grube C, Flepp M, Stockle M, Conen A, Beguelin C, et al. High number of potential transmitters revealed in a population-based systematic hepatitis C virus RNA screening among human immunodeficiency virus-infected men who have sex with men. Clin Infect Dis. 2019;68(4):561-8.

3. Weber R, Ruppik M, Rickenbach M, Spoerri A, Furrer H, Battegay M, Cavassini M, Calmy A, Bernasconi E, Schmid P, et al. Decreasing mortality and changing patterns of causes of death in the Swiss HIV cohort study. HIV Med. 2013;14(4):195-207. 
4. World Health Organization (WHO). Combating hepatitis B and C to reach eliminiation by 2030. In: Advocacy Brief. Geneva: World Health Organziation (WHO); 2016.

5. Midgard H, Weir A, Palmateer N, Lo Re V 3rd, Pineda JA, Macias J, Dalgard O. HCV epidemiology in high-risk groups and the risk of reinfection. J Hepatol. 2016;65(1 Suppl):S33-45.

6. Martin NK, Boerekamps A, Hill AM, Rijnders BJA. Is hepatitis C virus elimination possible among people living with HIV and what will it take to achieve it? J Int AIDS Soc. 2018;21(Suppl 2):e25062.

7. Glynn RW, Byrne N, O'Dea S, Shanley A, Codd M, Keenan E, Ward M, Igoe D, Clarke $S$. Chemsex, risk behaviours and sexually transmitted infections among men who have sex with men in Dublin, Ireland. Int J Drug Policy. 2018;52:9-15.

8. Schmidt AJ, Bourne A, Weatherburn P, Reid D, Marcus U, Hickson F, Network E. Illicit drug use among gay and bisexual men in 44 cities: findings from the European MSM internet survey (EMIS). Int J Drug Policy. 2016;38:4-12.

9. Girometti N, Devitt E, Phillips J, Nelson M, Whitlock G. High rates of unprotected anal sex and use of generic direct-acting antivirals in a cohort of MSM with acute HCV infection. J Viral Hepat. 2019;26(6):627.

10. Chan DP, Sun HY, Wong HT, Lee SS, Hung CC. Sexually acquired hepatitis C virus infection: a review. Int J Infect Dis. 2016:49:47-58.

11. Braun DL, Hampel B, Kouyos R, Nguyen H, Shah C, Flepp M, Stockle M, Conen A, Beguelin C, Kunzler-Heule P, et al. High cure rates with Grazoprevir-Elbasvir with or without ribavirin guided by genotypic resistance testing among human immunodeficiency virus/hepatitis $C$ viruscoinfected men who have sex with men. Clin Infect Dis. 2019;68(4):569-76.

12. Kouyos RD, Rauch A, Boni J, Yerly S, Shah C, Aubert V, Klimkait T, Kovari H, Calmy A, Cavassini M, et al. Clustering of HCV coinfections on HIV phylogeny indicates domestic and sexual transmission of HCV. Int J Epidemiol. 2014:43(3):887-96.

13. Swiss HIV Cohort Study (SHCS), Schoeni-Affolter F, Ledergerber B, Rickenbach M, Rudin C, Gunthard HF, Telenti A, Furrer H, Yerly S, Francioli P. Cohort profile: the Swiss HIV cohort study. Int J Epidemiol. 2010;39(5):1179-89.

14. van Sighem A, Vidondo B, Glass TR, Bucher HC, Vernazza P, Gebhardt M, de Wolf $F$, Derendinger $S$, Jeannin A, Bezemer $D$, et al. Resurgence of HIV infection among men who have sex with men in Switzerland: mathematical modelling study. PLoS One. 2012;7(9):e44819.

15. DeHart DD, Birkimer JC. Trying to practice safer sex: development of the sexual risks scale. J Sex Res. 1997;34(1):11-25

16. Rotheram-Borus M, Murphy D, Coleman C, Kennedy M, Reid H, Cline T, Birnbaum J, Futterman D, Levin L, Schneir A, et al. Risk acts, health care, and medical adherence among HIV+ youths in care over time. AIDS Behav. 1997;1(1):43-52.

17. Drumright LN, Little SJ, Strathdee SA, Slymen DJ, Araneta MR, Malcarne VL, Daar ES, Gorbach PM. Unprotected anal intercourse and substance use among men who have sex with men with recent HIV infection. J Acquir Immune Defic Syndr. 2006:43(3):344-50.

18. Daskalopoulou M, Rodger A, Phillips AN, Sherr L, Speakman A, Collins S, Elford J, Johnson MA, Gilson R, Fisher M, et al. Recreational drug use, polydrug use, and sexual behaviour in HIV-diagnosed men who have sex with men in the UK: results from the cross-sectional ASTRA study. Lancet HIV. 2014;1(1):e22-31.

19. Kouyos RD, Hasse B, Calmy A, Cavassini M, Furrer H, Stockle M, Vernazza PL, Bernasconi E, Weber R, Gunthard HF, et al. Increases in Condomless sex in the Swiss HIV cohort study. Open Forum Infect Dis. 2015;2(2):ofv077.

20. Rodger AJ, Cambiano V, Bruun T, Vernazza P, Collins S, van Lunzen J, Corbelli GM, Estrada V, Geretti AM, Beloukas A, et al. Sexual activity without condoms and risk of HIV transmission in Serodifferent couples when the HIV-positive partner is using suppressive antiretroviral therapy. JAMA. 2016;316(2):171-81.

21. Hess KL, Crepaz N, Rose C, Purcell D, Paz-Bailey G. Trends in sexual behavior among men who have sex with men (MSM) in high-income countries, 1990-2013: a systematic review. AIDS Behav. 2017;21:2811-34.

22. Champenois K, Seng R, Persoz A, Essat A, Gaud C, Laureillard D, Robineau O, Duvivier C, Yazdanpanah Y, Goujard C, et al. Recent trends in sexual behaviours among MSM followed since primary HIV-1 infection. AIDS. 2018.

23. Gonzalez-Baeza A, Dolengevich-Segal H, Perez-Valero I, Cabello A, Tellez MJ, Sanz J, Perez-Latorre L, Bernardino JI, Troya J, De La Fuente S, et al. Sexualized drug use (Chemsex) is associated with high-risk sexual behaviors and sexually transmitted infections in HIV-positive men who have sex with men: data from the U-SEX GESIDA 9416 study. AIDS Patient Care STDs. 2018:32(3):112-8.
24. Pufall EL, Kall M, Shahmanesh M, Nardone A, Gilson R, Delpech V, Ward H. Sexualized drug use ('chemsex') and high-risk sexual behaviours in HIVpositive men who have sex with men. HIV Med. 2018;19(4):261-70.

25. Bourne $A$, Weatherburn $P$. Substance use among men who have sex with men: patterns, motivations, impacts and intervention development need. Sex Transm Infect. 2017;93(5):342-6.

26. Pakianathan M, Whittaker W, Lee MJ, Avery J, Green S, Nathan B, Hegazi A. Chemsex and new HIV diagnosis in gay, bisexual and other men who have sex with men attending sexual health clinics. HIV Med. 2018;19(7):485-90.

27. Rosinska M, Gios L, Nostlinger C, Vanden Berghe W, Marcus U, Schink S, Sherriff $\mathrm{N}$, Jones AM, Folch $\mathrm{C}$, Dias $\mathrm{S}$, et al. Prevalence of drug use during sex amongst MSM in Europe: results from a multi-site bio-behavioural survey. Int J Drug Policy. 2018:55:231-41.

28. Schroder KE, Carey MP, Vanable PA. Methodological challenges in research on sexual risk behavior: II. Accuracy of self-reports. Ann Behav Med. 2003; 26(2):104-23.

\section{Publisher's Note}

Springer Nature remains neutral with regard to jurisdictional claims in published maps and institutional affiliations.
Ready to submit your research? Choose BMC and benefit from:

- fast, convenient online submission

- thorough peer review by experienced researchers in your field

- rapid publication on acceptance

- support for research data, including large and complex data types

- gold Open Access which fosters wider collaboration and increased citations

- maximum visibility for your research: over $100 \mathrm{M}$ website views per year

At BMC, research is always in progress.

Learn more biomedcentral.com/submissions 